\title{
Pelatihan Bahasa Inggris untuk Guru Sekolah Dasar di Yogyakarta di Masa Pandemi Covid-19
}

\author{
Adaninggar Septi Subekti ${ }^{1}$, Maria Raras Rumanti ${ }^{2}$ \\ 1, 2 Universitas Kristen Duta Wacana, Indonesia
}

\begin{abstract}
A B S T R A C T
ENGLISH TRAINING FOR ELEMENTARY SCHOOL EDUCATORS IN YOGYAKARTA IN THE TIME OF COVID-19. This community service activity was conducted in the form of an English training for eight teachers of an Elementary School in Yogyakarta, Indonesia. It was conducted from January 2020 up to April 2020. The elementary school in which the training was conducted was an inclusive school in the process of implementing English as Medium Instruction (EMI) policy. As such, its teachers' mastery of English became paramount important to facilitate young learners with all their individual differences. The training consisted of ten meetings focusing on giving instructions in class. The first up to the sixth meetings were conducted at the school in a face-to-face mode, whilst the seventh up to the tenth meetings were conducted online, mostly through tele-conferences, due to the Covid-19 pandemic compelling both facilitators and the training participants to work from home. In the ninth meeting, the participants sent their micro-teaching videos on giving effective instructions in class. In the last meeting, the facilitators gave constructive feedback based on the videos sent earlier on aspects that the participants had been good at and aspects that still needed improvements.
\end{abstract}

Keywords: Community Service, Giving Instructions, Micro-Teaching.

\begin{tabular}{llll}
\hline Received: & Revised: & Accepted: & Available online: \\
10.05 .2020 & 12.08 .2020 & 29.10 .2020 & 30.11 .2020 \\
\hline
\end{tabular}

\section{Suggested citation:}

Subekti, A. S., \& Rumanti, M. R. (2020). Pelatihan Bahasa Inggris untuk guru sekolah dasar di Yogyakarta di masa pandemi Covid-19. Jurnal Pengabdian Pada Masyarakat, 5(4), 1077-1086. https://doi.org/10.30653/002.202054.518

Open Access I URL: http://ppm.ejournal.id/index.php/pengabdian/article/view/518

\footnotetext{
${ }^{1}$ Corresponding Author: Program Studi Pendidikan Bahasa Inggris, Universitas Kristen Duta Wacana, Jalan dr Wahidin Sudirohusodo 5-25, Yogyakarta, 55224, Indonesia. Email: adaninggar@staff.ukdw.ac.id
} 


\section{PENDAHULUAN}

Peran guru dalam pendidikan sangatlah krusial. Guru menjadi pelaksana di lapangan yang terjun langsung dalam mendidik para siswa (Djaja, 2017; Hidayat, 2017). Karena itulah, guru sering disebut sebagai ujung tombak kualitas pendidikan (Hidayah, 2015). Karena peran guru yang begitu penting inilah, maka para guru dituntut untuk senantiasa melakukan pengembangan professional sehingga semakin mampu menjawab tantangan dunia pendidikan yang selalu dinamis dan cepat berubah (Djaja, 2017; Oviyanti, 2013).

Lebih khusus kepada pendidikan tingkat Sekolah Dasar (SD), keterampilan para guru dalam memfasilitasi para siswa untuk belajar sangatlah dibutuhkan. Para siswa yang masih dalam usia anak-anak memerlukan pendampingan ekstra yang mengharuskan para guru tidak saja mumpuni secara konten namun juga secara pedagogik (Agustin \& Pandia, 2014). Dalam hal ini, penggunaan bahasa yang efektif oleh guru menjadi jembatan strategis untuk memfasilitasi efektivitas pembelajaran. Karena itulah, peningkatan kemampuan guru dalam bahasa dinilai strategis untuk semakin memampukan mereka dalam memfasilitasi proses pembelajaran para siswa.

Atas kesadaran inilah, sebuah SD di Yogyakarta yang mengimplementasikan kurikulum Cambridge International Primary Program (CIPP) dan dalam proses menjadi sekolah yang mengimplementasikan English as Medium Instruction (EMI), menggunakan Bahasa Inggris sebagai bahasa pengantar pembelajaran (Jiang, Zhang, \& May, 2016), secara kontinyu menyelenggarakan pelatihan Bahasa Inggris bagi para guru-nya. Guruguru ini, meskipun secara umum memiliki kemampuan Bahasa Inggris yang lumayan, masih memerlukan pelatihan yang berkelanjutan untuk dapat mengimplementasikan EMI $100 \%$ di kelas. Apalagi studi juga menunjukkan bahwa guru-guru mata pelajaran yang notabene bukan dari jurusan Bahasa Inggris kemungkinan mengalami kendala bahasa tersendiri dalam mengajar para siswa dalam konteks EMI (lihat Denver, Jensen, Mees, \& Werther, 2016).

Hubungannya dengan itu, Universitas Kristen Duta Wacana (UKDW), yang memiliki empat nilai dasar yaitu Obedience to God (Menaati Allah), Walking in Integrity (Melangkah dalam Integritas), Striving for Excellence (Melakukan yang Terbaik), dan Service to the World (Melayani Dunia) (Universitas Kristen Duta Wacana, 2017), terpanggil untuk ikut ambil bagian dalam upaya peningkatan kualitas pendidik dan pendidikan pada umumya sebagai cerminan dari keempat nilai yang dipegang, terutama Service to the World. Karena itulah, disepakati adanya kerjasama dalam bentuk pelatihan Bahasa Inggris dalam payung pengabdian kepada masyarakat antara UKDW dan sekolah ini. Ditambah lagi, sekolah ini merupakan sekolah inklusif. Di sini para siswa sejak dini difasilitasi untuk menjadi orang yang bangga atas potensi diri sekaligus menghargai adanya keberagaman sekitarnya. Dengan menerapkan prinsip Education for All (pendidikan untuk semua), yang menghargai nilai-nilai perbedaan dan keberagaman seperti ras, agama, budaya, serta kebutuhan individu. Karena itulah, tidak mengherankan jika siswa berkebutuhan khusus sangat diterima di sekolah ini. Karakteristik sekolah yang begitu suportif terhadap perkembangan siswa yang beranekaragam juga menambah motivasi untuk turut ikut serta membantu meningkatkan kapasitas para guru-nya, secara kebahasaan dalam hal ini. 


\section{METODE}

Program pelatihan Bahasa Inggris untuk guru-guru SD ini merupakan lanjutan dari pelatihan serupa yang telah dilakukan pada semester gasal 2019/2020. Berbeda dengan pelatihan sebelumnya yang fokus kepada peningkatan keterampilan menulis laporan hasil belajar dan tata bahasa, pelatihan kali ini menitikberatkan pada peningkatan kemampuan para guru dalam memberikan instruksi yang efektif secara oral menggunakan Bahasa Inggris di dalam kelas.

Secara umum tujuan pelatihan ini adalah:

1) Peserta mampu menggunakan Bahasa Inggris dalam hal pelafalan dan tata bahasa dasar dengan percaya diri, nyaman, dan tepat

2) Peserta mampu mengajar mata pelajaran yang diampunya dengan Bahasa Inggris yang lebih baik dari sebelumnya

Pelatihan ini diikuti oleh delapan peserta guru-guru SD. Pelatihan ini pada awalnya direncanakan berlangsung setiap hari Jumat di salah satu ruang kelas sekolah tersebut, dalam sepuluh pertemuan, terdiri dari delapan pertemuan tatap muka berupa penyampaian materi, latihan, dan micro-teaching, dan satu pertemuan terakhir di mana fasilitator bertemu dengan para peserta satu per satu untuk mendiskusikan hasil belajar mereka. Masing-masing pertemuan tatap muka berlangsung selama 90 menit, dari jam 13.45-15.15. Dalam perkembangannya, meskipun kesepuluh pertemuan berhasil dilaksanakan, terdapat beberapa penyesuaian di tengah-tengah pelatihan karena adanya pandemi Covid-19 yang mengharuskan semua peserta bekerja dari rumah. Penyesuaian misalnya adalah penggantian metode tatap muka menjadi daring dan pemberian deadline yang lebih fleksibel mengingat kesibukan dan adaptasi para peserta dalam bekerja dari rumah, yang juga terjadi di banyak tempat (Daniel, 2020; Dubey \& Tripathi, 2020). Penyesuaian dan fleksibilitas sangat penting mengingat situasi yang tidak mendukung pelaksanaan pelatihan sesuai yang direncanakan. Secara rinci, sepuluh pertemuan yang telah berlangsung dapat dilihat pada Tabel 1.

Tabel 1. Kegiatan pelatihan

\begin{tabular}{lll}
\hline No & Hari, tanggal & Topik/materi \\
\hline 1. & Jumat, 24 Januari 2020 & Analisis kebutuhan para peserta \\
\hline 2. & Jumat, 7 Februari 2020 & Giving instructions (memberi instruksi) - pengenalan \\
\hline 3. & Jumat, 13 Februari 2020 & $\begin{array}{l}\text { Giving instructions - peserta memastikan pemahaman } \\
\text { siswanya terhadap instruksi yang diberikan }\end{array}$ \\
\hline 4. & Jumat, 28 Februari 2020 & Giving instructions - praktik di depan kelas \\
\hline 5. & Jumat, 6 Maret 2020 & Giving instructions - praktik di depan kelas (lanjutan) \\
\hline 6. & Jumat, 13 Maret 2020 & $\begin{array}{l}\text { Giving instructions - menggunakan kata kerja yang } \\
\text { bermacam-macam dalam instruksi }\end{array}$ \\
\hline 7. & Jumat, 20 Maret 2020 & $\begin{array}{l}\text { Giving instructions - error correction (melakukan } \\
\text { pembetulan kesalahan), penjelasan tugas video micro- } \\
\text { teaching }\end{array}$ \\
\hline 8. & Jumat, 3 April 2020 (daring) & Konsultasi tugas pembuatan video micro-teaching \\
\hline 9. & 13 April 2020 & $\begin{array}{l}\text { Pengumpulan video micro-teaching dalam bentuk } \\
\text { tautan Youtube }\end{array}$ \\
\hline 10. & 17 April 2020 (daring) & $\begin{array}{l}\text { Penyampaian perkembangan belajar para peserta oleh } \\
\text { fasilitator }\end{array}$ \\
\hline
\end{tabular}




\section{HASIL DAN PEMBAHASAN}

Pertemuan pertama dilaksanakan pada Jumat, 24 Januari 2020. Agenda utama pertemuan ini adalah pengenalan terhadap program English Training for Educators (Pelatihan Bahasa Inggris untuk Guru-Guru). Untuk mengetahui kebutuhan peserta secara lebih spesifik pada pertemuan pertama dilakukan needs analysis atau analisis kebutuhan yang sangat penting untuk dilakukan sebelum sebuah pelatihan bahasa dilakukan apalagi peserta adalah para guru yang membuat pelatihan ini dapat dikategorikan sebagai English for Specific Purposes (ESP), pelatihan Bahasa Inggris dengan tujuan khusus (Albassri, 2016). Data didapatkan dari survey kecil yang dilakukan secara daring dengan menggunakan mentimeter. Lima kebutuhan teratas yang muncul dalam survey ini kemudian didiskusikan bersama antara fasilitator dan peserta. Secara umum, dari hasil diskusi, para peserta menginginkan untuk mampu berbicara dalam Bahasa Inggris dengan lebih percaya diri dalam mengajar mata pelajaran CIPP yang digunakan di SD tersebut, meningkatkan kosakata, dan memberikan instruksi dalam Bahasa Inggris. Sesuai hasil analisis kebutuhan pada pertemuan pertama inilah, diputuskan bahwa fokus pelatihan adalah giving instructions (memberi instruksi/perintah) dengan di dalamnya menyelipkan materi pelafalan dan penambahan kosakata. Ditambah lagi, studi menunjukkan bahwa intruksi adalah tindak tutur yang paling sering digunakan oleh para guru SD (lihat Sofana, Khawa, Utami, \& Mulatsih, 2019). Instruksi guru di kelas sangat penting ketika mengajar murid SD inklusif, yang masih anak-anak dengan berbagai keberagamannya (Utami, 2018). Apabila instruksi tidak jelas, guru menjadi kurang mampu untuk mengatur kelasnya, kelas bisa cukup sulit dikendalikan dan akan sangat mempengaruhi ketercapaian tujuan pembelajaran (Sowell, 2017).

Materi giving instructions dimulai pada pertemuan kedua, Jumat, 7 Februari 2020. Sesi dimulai dengan sharing tentang pengetahuan para peserta bagaimana memberi instruksi dalam Bahasa Inggris sebagai aktivitas brainstorming (Oishi, 2015), untuk "memanggil kembali" apa yang para peserta sudah tahu sebelumnya terkait topik tersebut. Hal ini juga dilakukan untuk menyiapkan para peserta pada inti materi pembelajaran (Harmer, 2007). Aktivitas dilanjutkan dengan penjelasan struktur/tata bahasa dari kalimat instruksi. Para peserta kemudian praktik memformulasikan kalimat instruksi sederhana dan mendapatkan umpan balik dari fasilitator. Di sini para peserta dikenalkan pada Instruction Checking Questions (ICQ), yaitu cara guru untuk memastikan bahwa instruksi yang mereka sampaikan jelas dan dapat dimengerti oleh siswa-siswanya (Sowell, 2017). Contoh dari ICQ ini antara lain adalah "Do you need to do the task individually or in groups?" (Apakah kalian akan mengerjakan tugas ini sendiri atau dalam kelompok?) dan "Do you need to write the task on your papers or on the board?" (Apakah kalian akan menulis di kertas atau menulis di papan tulis?). Para peserta juga diminta untuk memberikan batas waktu (time limit) kepada siswa ketika memberi instruksi agar siswa dapat menjadi lebih fokus dan mengatur waktunya untuk mengerjakan tugas dengan lebih efisien (lihat Sowell, 2017). Sebagai aktivitas lanjutan di mana peserta dapat berlatih memformulasikan kalimat instruksi, dilakukan permainan uno stacko. Penggunaan permainan dalam sesi diharapkan dapat menjaga motivasi belajar para peserta, mengakomodasi cara belajar peserta yang berbeda-beda, 
dan membuat mereka terus tertarik pada aktivitas pembelajaran sehingga proses pembelajaran menjadi berkesan (meaningful learning) (Al-Masri \& Al-Najar, 2014).

Pertemuan ketiga dilaksanakan pada Jumat, 13 Februari 2020. Pertemuan ini masih berfokus pada materi giving instructions. Sesi dimulai dengan review materi pertemuan sebelumnya dan dilanjutkan dengan latihan lanjutan dalam bentuk permainan. Pada permainan kali ini, peserta membuat kelompok beranggotakan tiga orang. Mereka memformulasikan kalimat-kalimat instruksi berdasarkan visual cues/gambar contoh kegiatan/tugas siswa yang mereka lihat dalam presentasi slides fasilitator. Misal pada gambar kelas yang para siswanya sibuk sendiri, para peserta dapat membuat kalimat "Please be quiet. Pay attention to your teacher" (Tolong tenang. Perhatikan yang disampaikan Bapak/Ibu Guru). Penggunaan gambar visual bertujuan untuk memfasilitasi adanya variasi aktivitas, misal verbal dan visual, yang dapat meningkatkan efektivitas pembelajaran dan menjaga konsentrasi peserta pada materi pembelajaran (Harmer, 2007). Fasilitator membantu para peserta apabila selama melakukan permainan mengalami kesulitan maupun memiliki pertanyaan. Sebelum sesi diakhiri, peserta diberikan tugas rumah berupa persiapan untuk melakukan praktik giving instruction dengan menggunakan materi CIPP yang mereka biasa gunakan dalam suasana kelas di mana mereka menjadi guru di kelas tersebut. Praktik ini direncanakan berlangsung selama 15 menit/peserta dan akan dilaksanakan pada pertemuan keempat.

Pada pertemuan keempat, 28 Februari 2020, seperti yang telah dijadwalkan, peserta melakukan praktik giving instructions di mana mereka mengajar mata pelajaran yang diampu dengan para peserta lain berperan sebagai siswa SD. Sebelumnya, fasilitator memberikan kriteria instruksi yang efektif yang telah dipelajari sebelumnya, antara lain: siswa-siswa harus memperhatikan, instruksi harus pendek dan jelas, serta instruksi dapat disertai gestur yang mendukung dan relevan (Sowell, 2017). Seringkali gestur disertai juga dengan ekspresi wajah yang mendukung (Sowell, 2017). Fasilitator memberikan umpan balik kepada masing-masing peserta yang telah melakukan praktik.

Karena masih ada dua peserta yang belum mendapat kesempatan praktik di depan kelas pada pertemuan keempat, pada pertemuan kelima, Jumat, 6 Maret 2020, mereka diberi kesempatan yang sama, dengan didahului review pertemuan sebelumnya oleh fasilitator. Dua peserta ini ternyata belum melakukan persiapan yang matang, sehingga penampilan mereka belum begitu bagus. Karena itulah, setelah mereka praktik, fasilitator meminta dua peserta ini untuk melakukan praktik sekali lagi. Sebelum melakukan praktik yang kedua kali, mereka diminta berlatih dengan peserta-peserta lain dalam kelompok kecil untuk persiapan. Terkait hal ini, studi menunjukkan bahwa ketika pembelajar berlatih bahasa dalam kelompok kecil, mereka cenderung lebih berani ambil risiko dan memiliki kepercayaan diri yang lebih tinggi (contoh: Subekti, 2018,2020 ). Dua peserta ini diminta menulis instruksi yang rencananya akan dikatakan di depan kelas. Setelah kedua peserta tersebut merasa siap, mereka diminta kembali melakukan praktik di depan kelas dan, benar saja, setelah diberi kesempatan berlatih dalam kelompok kecil, penampilan mereka, baik secara produksi bahasa maupun kepercayaan diri, menjadi jauh lebih baik.

Pertemuan keenam diadakan pada Jumat, 13 Maret 2020. Fokus pertemuan ini adalah peserta belajar kosakata verbs (kata kerja) yang dapat digunakan dalam memberi 
instruksi di kelas. Sebuah studi menunjukkan bahwa word games (permainan kata) adalah aktivitas yang mampu meningkatkan penguasaan kosakata (contoh: Al-Masri \& Al-Najar, 2014). Karena itulah, aktivitas pada pertemuan ini dibuka dengan permainan chained words (kata berantai). Peserta diminta menyebutkan satu kata kerja, kemudian peserta disampingnya harus menyebutkan satu kata kerja yang lain yang diawali dengan huruf terakhir kata kerja sebelumnya. Misalnya, salah satu peserta menyebut kata kerja " $g o$ " (pergi), maka peserta di sampingnya harus menyebutkan satu kata kerja yang diawali dengan huruf " $\mathrm{o}$ ", huruf terakhir dari kata "go", misalnya kata kerja "open" (buka), demikian seterusnya. Permainan ini memfasilitasi para peserta untuk memikirkan kata-kata kerja baru yang mereka belum begitu familiar. Dalam hal ini, fasilitator memberi tahu mereka cara mencari kata kerja di internet dengan menggunakan kata kunci, misalnya "verbs starting with ' $o^{\prime}$ " (kata kerja berawalan huruf "o"). Setelah para peserta melakukan permainan chained words secara bersama-sama, mereka diminta menulis lima kata kerja berantai secara individu. Kemudian, mereka diminta untuk membuat kalimat instruksi yang jelas menggunakan kata-kata tersebut. Fasilitator membantu peserta apabila mereka mengalami kesulitan dan memberikan umpan balik.

Pertemuan ketujuh pada Jumat, 20 Maret 2020 diadakan secara daring melalui aplikasi Zoom. Hal ini sebenarnya tidak direncanakan sebelumnya. Pandemi Covid-19 yang melanda dunia, termasuk Indonesia, membuat para siswa belajar di rumah dan para guru serta karyawan bekerja dari rumah. Karena itulah, pertemuan yang rencananya diadakan secara tatap muka secara langsung di sekolah harus diganti menjadi tele-conference. Pada pertemuan daring perdana ini, peserta diajak untuk mereview giving instructions melalui permainan Kahoot dengan cara memberikan koreksi terhadap kalimat yang salah. Studi menunjukkan bahwa error correction (aktivitas membetulkan kesalahan) dapat meningkatkan pemahaman terhadap aspek tata bahasa (contoh: Coyle \& de Larios, 2014), sehingga diharapkan aktivitas ini dapat memfasilitasi peserta untuk mengimplementasikan pengetahuan teori mereka tentang tata bahasa kalimat instruksi untuk membetulkan contoh-contoh kalimat instruksi yang salah tata bahasanya. Sementara itu, penggunaan aplikasi Kahoot didasarkan pada tujuan untuk menciptakan suasana belajar yang santai namun berkesan (Dellos, 2015). Pada pertemuan ini juga diadakan kuis yang dilakukan dengan cara menjawab pertanyaan dalam Google Form. Pada kuis ini, para peserta diminta mengurutkan katakata acak sesuai tata bahasa kalimat instruksi yang benar dan menulis instruksi yang relevan sesuai gambar. Kemudian fasilitator memberikan tugas membuat video microteaching berfokus pada pemberian instruksi yang efektif di konteks kelas masingmasing. Video ini kemudian harus dikirimkan kepada fasilitator untuk mendapatkan umpan balik. Situasi pertemuan daring melalui Zoom dapat dilihat pada Gambar 1.

Pertemuan kedelapan pada Jumat, 3 April 2020 dilakukan melalui kombinasi penggunaan Google site untuk pemberian tugas dan WhatsApp chat untuk pemberian umpan balik dan konsultasi. Pertemuan ini fokus pada persiapan para peserta untuk membuat video micro-teaching yang menitikberatkan pada giving instructions.

Sekitar dua minggu setelah pertemuan kedelapan, para peserta mengirimkan tautan video micro-teaching yang fokus pada giving instructions yang telah diunggah ke Youtube. Pengumpulan ini dianggap sebagai pertemuan kesembilan. 


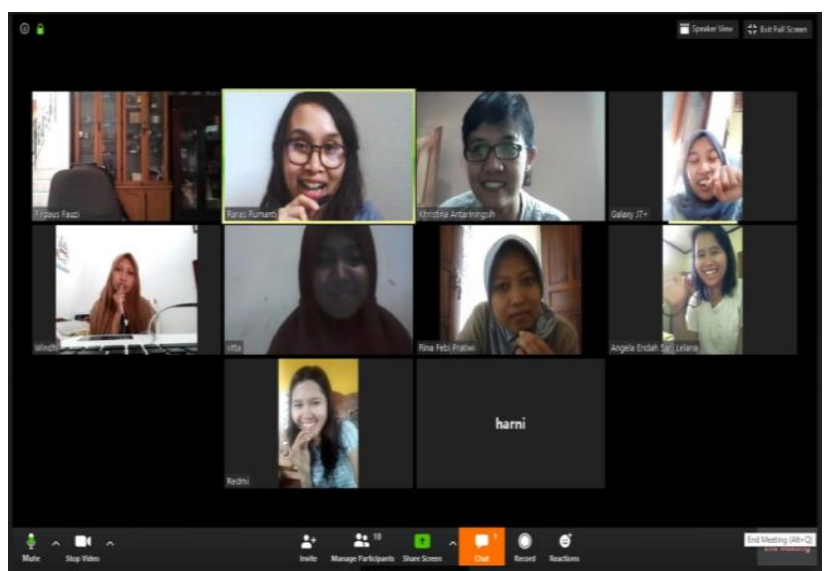

Gambar 1. Pertemuan daring melalui Zoom

Pada pertemuan kesepuluh, atau terakhir, Jumat, 17 April 2020, fasilitator melakukan tele-conference dengan para peserta secara bergantian, satu per satu, untuk memberikan umpan balik terhadap penampilan mereka dalam video micro-teaching yang dikirimkan sebelumnya. Mereka juga mendapatkan umpan balik tentang performa dan perkembangan belajar mereka selama mengikuti pelatihan. Pemberian umpan balik di akhir pelatihan adalah suatu praktik baik mengingat umpan balik memungkinkan para peserta pelatihan mengetahui level kemampuan mereka secara kebahasaan sekaligus mengetahui hal-hal yang sudah berhasil mereka capai dan halhal yang masih harus ditingkatkan (Klimova, 2015; Petchprasert, 2012). Hasil belajar para peserta ditulis secara kualitatif dalam bentuk paragraf dan diserahkan kepada para peserta pada hari itu. Secara kuantitatif, hasil belajar mereka dapat dilihat pada Tabel 2.

Tabel 2. Nilai kuis dan micro-teaching peserta

\begin{tabular}{lll}
\hline Peserta & Nilai kuis (tertulis) & Nilai micro-teaching (oral) \\
\hline Peserta 1 & 92 & 75 \\
\hline Peserta 2 & [absen] & 55 \\
\hline Peserta 3 & 89 & 100 \\
\hline Peserta 4 & 82 & 70 \\
\hline Peserta 5 & 83 & 80 \\
\hline Peserta 6 & 76 & 55 \\
\hline Peserta 7 & 84 & 95 \\
\hline Peserta 8 & [absen] & 45 \\
\hline
\end{tabular}

Dari Tabel 2 dapat dilihat bahwa secara umum para peserta memiliki pemahaman yang relatif baik terhadap materi yang diberikan. Kemampuan peserta 2, peserta 6, dan peserta 8 mungkin sedikit di bawah yang lain, namun secara umum, kedelapan peserta pelatihan memiliki motivasi yang tinggi dalam mengikuti pelatihan. Melakukan microteaching dalam bentuk rekaman video tentu memiliki kesulitan tersendiri dibandingkan jika para peserta dapat langsung mempraktikkannya di depan kelas. Namun demikian, para peserta yang tentunya sibuk dalam melakukan kegiatan pengajaran dari rumah masih menyempatkan untuk membuat video micro-teaching tersebut dengan kualitas yang relatif baik. Hal ini menunjukkan dorongan yang besar untuk terus belajar. 
Selanjutnya, materi pelatihan yang berfokus pada giving instructions memungkinkan para peserta untuk secara lebih dalam dan kontinyu mengasah kemampuan mereka di area itu sehingga di akhir pelatihan kemampuan mereka dalam memberikan instruksi yang efektif dalam Bahasa Inggris sangat terlihat. Tentunya masih ada beberapa kekurangan yang masih harus dibenahi, seperti pronunciation (pelafalan), bagaimana memastikan para siswa mereka memahami instruksi, bagaimana menggunakan istilah yang mudah dipahami, dan bagaimana menggunakan bahasa tubuh yang mendukung kejelasan instruksi verbal. Namun demikian, para peserta dapat terus meningkatkan kemampuan mereka asalkan mereka mau untuk terus belajar, tidak takut salah, dan percaya diri.

\section{SIMPULAN}

Umpan balik dari para peserta terkait pelatihan secara umum diperoleh melalui WhatsApp chat dan didapatkan hasil antara lain sebagai berikut. Penyampaian materi yang tidak terlalu banyak, fokus pada giving instructions, memungkinkan para peserta memiliki cukup waktu untuk memperdalam materi tersebut. Peserta juga menyadari bahwa sebagaimanapun materi pengajaran dalam micro-teaching telah dipersiapkan, selalu ada yang kurang. Misalnya penggunaan kosakata harus diformulasikan sesederhana mungkin karena para siswa yang notabene masih anak-anak mungkin saja mengalami kesulitan dalam memahaminya.

Selanjutnya, ada beberapa usulan kegiatan pelatihan semester depan dari para peserta. Pertama adalah pelatihan tata bahasa yang sederhana yang dipakai dalam percakapan maupun pengajaran sehari-hari. Selanjutnya, aspek pelafalan juga menjadi perhatian. Ada pula yang berpandangan bahwa kemampuan berbicara menggunakan Bahasa Inggris dalam forum diskusi yang dinamis dan santai perlu ditingkatkan.

Dari umpan balik terhadap pelaksanaan pelatihan sekaligus usulan kegiatan ini, dapat disimpulkan bahwa pelatihan ini, meskipun membawakan materi yang cukup sederhana, dapat dianggap cukup berhasil. Karena itulah, pelatihan-pelatihan di masa mendatang perlu juga mempertimbangkan aspek kedalaman penyampaian materi daripada sekedar aspek keluasan. Selanjutnya animo yang tinggi dari para peserta untuk dapat memperdalam pemahaman tata bahasa dapat difasilitasi dengan pelatihan yang berfokus pada formulasi kalimat sederhana baik secara lisan maupun tertulis. Kemampuan dalam memformulasikan kalimat nantinya dapat menjadi batu loncatan untuk para peserta bisa melakukan diskusi dalam Bahasa Inggris dengan pelafalan yang relatif baik dan mudah dipahami.

Terakhir, dalam pelatihan ini, tidak hanya para peserta yang belajar dari para fasilitator, namun fasilitator-pun belajar banyak dari para peserta. Mengajar anak-anak dengan latar belakang yang berbeda-beda dalam kelas inklusif memerlukan tidak hanya kemampuan profesional namun juga pedagogik yang mumpuni seperti kesabaran yang tinggi. Prinsip bahwa no child shall be left behind (tidak boleh ada anak yang ditinggalkan) harus selalu dipegang teguh (Padmadewi \& Artini, 2017). 


\section{REFERENSI}

Agustin, L. D., \& Pandia, W. S. S. (2014). Pemahaman pedagogik guru dalam mengajar anak berkebutuhan khusus di sekolah inklusi. Provitae: Jurnal Psikologi Pendidikan, 6(1), 73-98.

Al-Masri, A., \& Al-Najar, M. (2014). The effect of using word games on primary stage students' achievement in English language vocabulary in Jordan. American International Journal of Contemporary Research, 4(9), 144-152.

Albassri, I. A. (2016). Needs-analysis-informed teaching for English for Specific Purposes [Pembelajaran Bahasa Inggris untuk tujuan khusus berdasarkan analisis kebutuhan]. California State University, San Bernardino.

Coyle, Y., \& de Larios, J. R. (2014). Exploring the role played by error correction and models on children's reported noticing and output production in a L2 writing task. Studies in Second Language Acquisition, 36, 451-485. https://doi.org/10.1017/S0272263113000612

Daniel, S. J. (2020). Education and the COVID-19 pandemic [Pendidikan dan pandemi Covid-19]. Prospects. https://doi.org/10.1007/s11125-020-09464-3

Dellos, R. (2015). Kahoot! A digital game resource for learning [Kahoot! Permainan untuk belajar]. International Journal of Instructional Technology and Distance Learning, 12(4), 47-52.

Denver, L., Jensen, C., Mees, I. M., \& Werther, C. (2016). Good enough to teach? A study of EMI lecturers' language skills and metadiscourse. Moderna Språk, (2), 46-72.

Djaja, S. (2017). Harapan dan tantangan guru pembelajar moda daring. Jurnal Ilmiah Ilmu Pendidikan, Ilmu Ekonomi, dan Ilmu Sosial, 10(2).

Dubey, A. D., \& Tripathi, S. (2020). Analysing the sentiments towards work-from-home experience during COVID-19 pandemic. Journal of Innovation Management (JIM), 8(1), 13-19.

Harmer, J. (2007). How to teach English [Bagaimana mengajar Bahasa Inggris]. Essex: Pearson Education Limited.

Hidayah, N. (2015). Memupuk kompetensi dan profesionalisme guru Sekolah Dasar Muhammadiyah. Dalam Seminar Nasional Pendidikan PGSD UMS \& HDPGSDI Wilayah Jawa (pp. 337-345).

Hidayat, R. (2017). Perbaikan komitmen organisasional guru dalam perspektif kepemimpinan kepala sekolah dan kepuasan kerja. Pedagogia, 9(1), 490-496.

Jiang, L., Zhang, L. J., \& May, S. (2016). Implementing English-medium instruction (EMI) in China: Teachers' practices and perceptions, and students' learning motivation and needs. International Journal of Bilingual Education and Bilingualism, 1-13. https://doi.org/10.1080/13670050.2016.1231166

Klimova, B. (2015). The role of feedback in EFL classes. In Procedia - Social and Behavioral Sciences, 199 (pp. 172-177). https://doi.org/10.1016/j.sbspro.2015.07.502 
Oishi, T. (2015). Applying brainstorming techniques to EFL classroom. NII Electronic Library Service, 121-127.

Oviyanti, F. (2013). Tantangan pengembangan pendidikan keguruan di era global. Jurnal Pendidikan Islam, 7(2), 267-283.

Padmadewi, N. N., \& Artini, L. P. (2017). Teaching English to a student with Autism Spectrum Disorder in regular classroom in Indonesia. International Journal of Instruction, 10(3), 159-176.

Petchprasert, A. (2012). Feedback in second language teaching and learning. US-China Foreign Language, 10(4), 1112-1120.

Sofana, N. F., Khawa, Z. Y. N., Utami, N. C., \& Mulatsih, S. (2019). Tindak tutur yang digunakan para guru SD Islam Bilingual An-Nisa Semarang dalam proses belajar mengajar di kelas. In Prosiding SENDI_U (pp. 728-733).

Sowell, J. (2017). Good instruction-giving in the second-language classroom. In English Teaching Forum (Vol. 55, No. 3, pp. 10-19). US Department of State. Bureau of Educational and Cultural Affairs, Office of English Language Programs, SA-5, 2200 C Street NW 4th Floor, Washington, DC 20037.

Subekti, A. S. (2018). An exploration of foreign language anxiety in the Indonesian university context: Learners' and teachers' voices. TEFLIN Journal, 29(2), 219-244.

Subekti, A. S. (2020). Self-perceived communication competence and communication apprehension: A study of Indonesian college students. EduLite: Journal of English Education, Literature, and Culture, 5(1), 14-31.

Universitas Kristen Duta Wacana. (2017). Nilai-nilai universitas. Retrieved August 4, 2019, from https://www.ukdw.ac.id/profil/nilai-nilai-ukdw/

Utami, N. E. B. (2018). Layanan guru kelas bagi siswa slow learner di sekolah inklusi (SDN Bangunrejo 2 Yogyakarta). Al-Bidayah, 10(2), 271-290.

\section{Copyright and License}

This is an open access article distributed under the terms of the Creative Commons Attribution 4.0 International License, which permits unrestricted use, distribution, and reproduction in any medium, provided the original work is properly cited. (C) 2020 Adaninggar Septi Subekti, Maria Raras Rumanti. 